\title{
RANCANG BANGUN HIDROPONIK BERBASIS MIKROKONTROLER UNTUK TANAMAN SELADA DI KECAMATAN BATULICIN KABUPATEN TANAH BUMBU
}

\author{
Halim, Anwar \\ Politeknik Batullicin, Kalimantan Selatan, Indonesia \\ halimrahimst@gmail.com
}

\begin{abstract}
One of sub-districts in South Kalimantan, which is the route in the process of shipping coal from various locations, both national and international, because of its strategic location. According to data from central statistics agency, Tanah Bumbu district consists of 10 sub-districts starting from Kusan Hilir sub-district to Mentewe sub-district. Batulicin District has an area of $127.71 \mathrm{~km}^{2}$. Community development in Batulicin sub-district is relatively advanced, even though some areas are considered forest areas. However, aspects of information and availability of needs are generally still very smooth. The economic development of this area is reasonably fast so that advances in technology and information have made this sub-district a modern society. Batulicin Subdistrict, apart from being an area rich in mining products, is also suitable for agricultural land. However, the availability of arable land is still minimal because the land is filled with soils with high iron content. With the development of technology and information on the availability of this land, it can be used for the use of appropriate technology in agriculture, namely hydroponic plants. The design and construction of tools are used as a means of utilizing current technology to provide solutions to utilize existing land with easier management. Also, local activities cover Tanah Bumbu area and its surroundings so that the dissemination of information and technology is not evenly distributed. Therefore, along with a team of lecturers and students carried out Community Service activities with the theme Microcontroller-Based Hydroponic Design for Lettuce Plants, aiming to improve Human Resources, especially hydroponic agriculture, as well as a means of advancing the economy in the field of hydroponic plant agriculture in Batulicin subdistrict. With more accessible and more efficient management.
\end{abstract}

Keywords: Lettuce Hydroponic Design; Microcontroller based; Batulicin District

\footnotetext{
Abstrak

Salah satu wilayah kecamatan yang berada dikalimantan selatan yang merupakan jalur dalam proses pengiriman batubara dari berbagai lokasi baik berskala nasional dan internasional karena letaknya yang strategis. Menurut data badan pusat statistik, kabupaten Tanah Bumbu terdiri dari 10 kecamatan dimulai dari kecamatan Kusan Hilir sampai kecamatan Mentewe. Kecamatan Batulicin mempunyai luas wilayah $127,71 \mathrm{~km}^{2}$. Perkembangan Masyarakat di kecamatan Batulicin terbilang maju, meskipun beberapa daerah terbilang kawasan hutan, namun aspek informasi dan ketersediaan kebutuhan secara umum masih sangat lancar. Perkembangan ekonomi daerah ini terbilang cepat sehingga kemajuan teknologi dan informasi menjadikan kecamatan ini menjadi masyarakat moderen. Kecamatan Batulicin selain daerah yang kaya akan hasil tambang, juga baik untuk lahan pertanian, namun ketersediaan lahan garapan masih minim disebabkan daratan yang dipenuhi tanah berkadar besi tinggi. Dengan perkembangan teknologi dan informasi ketersediaan lahan ini dapat difungsikan untuk pemanfaatan teknologi tepat guna dibidang pertanian yaitu tanaman hidroponik. Rancang bangun alat digunakan sebagai sarana pemanfaatan teknologi saat ini guna memberikan solusi untuk memanfaatkan lahan yang ada dengan pengelolaan yang lebih mudah. Selain itu, kegiatan bersifat lokal mencakup daerah Tanah Bumbu dan sekitarnya sehingga penyebaran informasi dan teknologinya tidak merata. Oleh karena itu saya beserta tim dosen dan mahasiswa melakukan kegiatan Pengabdian kepada Masyarakat dengan mengangkat tema Rancang Bangun Hidroponik Berbasis Mikrokontroler untuk Tanaman Selada, bertujuan untuk meningkatkan Sumber Daya Manusia khususnya pertanian hidroponik, juga sebagai salah satu sarana memajukan perekonomian dibidang pertanian tanaman hidroponik di kecamatan Batulicin, dengan pengelolaan yang lebih mudah dan efisien.
} 
Kata Kunci: Rancang Bangun Hidroponik Selada; Berbasis Mikrokontroler; Kecamatan Batulicin

Submitted: 2020-09-17

Revised: 2020-09-30

Accepted: $2020-10-05$

\section{Pendahuluan}

Tanah bumbu merupakan kabupaten yang terdiri dari beberapa kecamatan berdasarkan data badan pusat statistik diantaranya kecamatan Kusan Hilir Sungai Loban, Satui, Angsana, Kusan Hulu, Kuranji, Batulicin, Karang Bintang, Simpang Empat dan Mantewe, salah satu kecamatan yang berkembang dengan cepat yaitu kecamatan Batulicin yang merupakan jalur penting dalam proses pengiriman batu bara dari Kalimantan Selatan ke berbagai lokasi ditanah air dan internasional. Dari letaknya yang strategis kecamatan Batulicin terletak di tepi selat laut yang menghubungkan antara laut Jawa dengan selat Makassar. Hal tersebut membuat kecamatan Batulicin menjadi terbilang maju dari segi informasi maupun ketersediaan kebutuhan secara umum. Perkembangan perekonomian daerah ini terbilang cepat sehingga kemajuan teknologi dan informasi menjadikan kondisi daerah ini moderen.

Luas wilayah kecamatan Batulicin $127,71 \mathrm{~km}^{2}$ nilai ini sesuai yang tercantum dalam data Badan Pusat Statistik tahun 2015. Umumnya di kabupaten Tanah Bumbu sebagian besar lahan masih berupa hutan dengan kondisi tanah merah mempunyai kadar besi tinggi sehingga, beberapa lokasi mengalami kendala untuk digunakan sebagai lahan pertanian, sementara Sumber Daya Manusia dibidang pertanian sangat memadai. Bagi masyarakat lokal pertanian dilakukan dengan pemilihan tanaman seperti karet, ketapang, dan jenis tanaman lain mempunyai akar kuat yang mampu tumbuh diberbagai medan tanah, biasanya untuk pertanian khususnya tanaman selada dibeberapa tempat mengalami kendala disebabkan karena faktor tanah dan temperatur tumbuh, sehingga untuk memperoleh selada beberapa diantaranya harus menyuplai dari daerah lain yang cukup lumayan jauh, ada yang memanfaatkan pertanian dengan lokasi yang terbatas dan sebagiannya memanfaatkan pertanian hidroponik yang kapasitasnya juga terbatas dengan jumlah kebutuhan pasar masyarakat lokal. Hal tersebut mampu mempengaruhi kesenjangan ekonomi khususnya dibidang pertanian.

Kecamatan Batulicin dengan potensi wilayah yang luas dapat difungsikan sebagai lahan pertanian. Namun ketersediaan lahan dengan faktor tanah dan temperatur lingkungan yang tidak mendukung tersebut, dengan lokasi yang sangat terbatas hanya dimanfaatkan oleh beberapa masyarakat lokal untuk bertani hidroponik yang sifatnya belum menyeluruh. Selain itu rancang bangun alat digunakan sebagai sarana pemanfaatan teknologi saat ini guna memberikan solusi untuk memanfaatkan lahan yang ada dengan pengelolaan yang lebih mudah dan efisien. Pemanfaatan modul mikrokontroler pada rancang bangun alat menjadikan alat beroperasi secara otomatis, modul mikrokontroler yang digunakan adalah modul termostat kontroler, fungsi dari modul ini untuk menjaga temperatur sekitar menjadi lebih stabil dengan rentan pembacaan temperatur 0 sampai $100{ }^{\circ} \mathrm{C}$ yang dilengkapi dengan sensor temperatur, modul ini dijadikan sebagai sistem otomatis pendinginan secara pengembunan melalui kabut nozzle dengan low cost, spesifikasi modul memerlukan listrik/battrei dalam pengoperasiannya sebesar $12 \mathrm{~V}$ DC, pada modul telah dilengkapi dengan relai sebagai pemutus dan penyambung arus listrik secara otomatis, selanjutnya motor langkah pada 
alat berfungsi agar temperatur sekitar tanaman lebih merata. Masih banyak potensi dibidang pertanian yang mampu dikelola dan memanfaatkan lahan yang ada dengan metode hidroponik. Apabila lahan yang ada mampu dimanfaatkan dengan pengelolaan lahan yang baik, maka dapat memajukan perekonomian dan mengurangi tingkat pengangguran. Disisi lain juga potensi Sumber Daya Alam daerah kecamatan Batulicin, dapat dijadikan tempat rekreasi dengan membangun anjungan pesisir pelabuhan batang.

Tujuan dari Rancang Bangun Hidroponik Berbasis Mikrokontroler untuk tanaman selada adalah untuk memanfaatkan potensi lahan yang ada dan SDM di kecamatan Batulicin khususnya untuk kalangan usia muda yang energik dan produktif. sementara pencapaian sasaran secara khusus diantaranya:

1. Pemanfaatan teknologi untuk pengelolaan lahan yang cukup luas.

2. Meningkatkan dan mengembangkan minat pengetahuan tentang teknologi tepat guna khususnya mikrokontroler dalam pengelolaan tanaman selada yang lebih mudah dan efisien.

3. Mengurangi tingkat pengangguran yang memicu munculnya tindakan kriminalitas di usia muda yang energik dan produktif.

Beberapa permasalahan pada rancang bangun alat adalah sebagai berikut:

1. Rancang bangun alat yang dibuat berskala contoh untuk pengembangan alat yang cakupannya lebih besar.

2. Tanaman hidroponik pada awalnya tidak menggunakan sistem kontrol untuk pengembunan khususnya untuk tanaman selada yang tumbuh pada temperatur 1520 derajat celcius, dengan ketinggian 500 - 2000 m diatas permukaan laut.

3. Langkanya tumbuhan selada, sementara permintaan pasar lokal yang lebih besar.

Untuk faktor pendukung diantaranya adalah:

1. Pembuatan rancang bangun alat beberapa bagiannya memanfaatkan barang yang telah terpakai untuk mengurangi sampah/limbah seperti: rangka alat yang terbuat dari besi cor diameter $10 \mathrm{~mm}$, pipa paralon, dop penutup, bearing center tengah sebagai penyangga rangka alat.

2. Modul mikrokontroler termostat yang digunakan pada rancang bangun alat mudah diperoleh dipasaran dengan harga yang murah.

3. Dukungan dari Kementrian Pendamping Desa tingkat kabupaten tanah bumbu yang memberikan semangat untuk pengembangan alat yang lebih maju dengan penambahakan fitur yang baru kedepan.

Untuk faktor penghambat yaitu:

1. Sikap yang tidak peduli dari masyarakat sekitar lingkungan untuk mengembangkan metode ini.

2. Pemikiran yang instan dari masyarakat sekitar sehingga mereka lebih memilih untuk menggunakan metode yang biasa, dibandingkan menggunakan metode ini.

3. Kurangnya pemahaman sebagian masyarakat tentang perkembangan teknologi yang lebih maju.

\section{Metode}


Pelaksanaan kegiatan Pengabdian kepada Masyarakat dilakukan selama 15 hari, yang dimulai pada minggu ke empat bulan April 2020 di kecamatan Batulicin, kabupaten Tanah Bumbu, adapun untuk langkah kegiatan PkM berdasarkan sebagai berikut:

Tabel 1. Langkah pelaksanaan kegiatan

\begin{tabular}{|c|c|}
\hline \multicolumn{2}{|c|}{ Tahap persiapan } \\
\hline Metode pengumpulan data & $\begin{array}{l}\text { Identifikasi permasalahan yang dihadapi dengan } \\
\text { mengikuti forum kegiatan pendamping desa yang } \\
\text { diadakan oleh kementrian pendamping desa. }\end{array}$ \\
\hline Pembentukan tim PkM & $\begin{array}{l}\text { Pembentukan tim yang terdiri dari dosen dan } \\
\text { mahasiswa yang disesuaikan dengan bidang } \\
\text { pengetahuan untuk menyelesaikan permasalahan } \\
\text { yang dihadapi oleh masyarakan khususnya dibidang } \\
\text { pertanian saat ini. }\end{array}$ \\
\hline Pembuatan proposal & $\begin{array}{l}\text { Pembuatan proposal untuk menawarkan solusi } \\
\text { permasalahan yang dihadapi mengenai teknologi } \\
\text { tepat guna berbasis mikrokontroler. }\end{array}$ \\
\hline $\begin{array}{l}\text { Koordinasi tim kepada kementrian } \\
\text { pendamping desa tingkat kabupaten } \\
\text { Tanah Bumbu }\end{array}$ & $\begin{array}{l}\text { Pelaksanaan kegiatan yang dilakukan di gedung } \\
\text { kapet desa simpang empat dinas pertanian dan } \\
\text { perkebunan. }\end{array}$ \\
\hline $\begin{array}{l}\text { Rancang bangun alat hidroponik } \\
\text { berbasis mikrokontroler }\end{array}$ & $\begin{array}{l}\text { Pembuatan rancangan alat sederhana dan pembelian } \\
\text { bagian alat diantaranya motor DC stepper digunakan } \\
\text { untuk memutar tanaman hidroponik pada rangka } \\
\text { yang dibentuk lingkaran guna untuk pengembunan } \\
\text { yang merata pada hidroponik dengan pengujian } \\
\text { tanaman selada, modul mikrokontroler temostat yang } \\
\text { berfungsi untuk pengkondisi temperatur sekitar } \\
\text { hidroponik yanq diletakkan ditenqah rangka dari alat. }\end{array}$ \\
\hline
\end{tabular}

\section{Tahap pelaksanaan}

Pelaksanaan kegiatan dilakukan di gedung dinas perkebunan desa simpang empat

Perancangan alat hidroponik berbasis Dilaksanakan dalam 15 hari kerja selama kegiatan mikrokontroler

PkM berlangsung.

Melakukan pengujian alat sebelum Dilaksanakan uji coba dengan pemilihan tanaman ditampilkan digedung kegiatan selada air sekaligus pengujian fungsi-fungsi alat serta mikrokontroler yang terpasang, diantaranya uji sensor temperatur, uji motor langkah (stepper) dan uji kabut nozzle, apakah telah berjalan dengan baik.

Dilakukan pengujian kembali untuk memastikan Melakukan pengecekan kembali bagianbahwa alat berjalan sesuai dengan kondisi bagian alat setelah berada pada lokasi pengaturan pembacaan temperatur pada modul kegiatan termostat kontroler. 


\section{Tahap akhir}

Promosi, pengenalan dan fungsi serta Promosi dan pengenalan serta pengoperasian alat pengoperasian dari alat dilakukan pada saat kegiatan berlangsung yang dilaksanakan di gedung dinas pertanian dan perkembunan kapet berlokasi di desa Simpang Empat kecamatan Batulicin, kegiatan ini merupakan kegiatan promosi kerajinan setiap desa tingkat kabupaten berupa lomba, untuk menarik masyarakat sekitar agar lebih kreatif.

Hasil yang diperoleh setelah pelaksanaan kegiatan Pengabdian kepada Masyarakat (PkM) adalah sebagai berikut:

1. Peningkatan pengetahuan tentang teknologi tepat guna khususnya teknologi mikrokontroler dalam pengelolaan tanaman selada yang lebih mudah dan efisien.

2. Pemanfaatan barang yang telah terpakai untuk mengurangi sampah dengan menciptakan lingkungan yang bersih dan sehat.

3. Mampu bertani hidroponik dengan tanaman selada yang tumbuh pada temperatur 15-20 derajat celcius dengan sistem pengembunan otomatis menggunakan sensor temperatur dari modul mikrokontroler termostat.

Harapan kedepan:

1. Diharapkan pengembangan teknologi tepat guna khususnya dibidang hidroponik untuk pertanian mampu diterapkan lebih luas untuk efisien waktu.

2. Diharapkan mikrokontroler sebagai teknologi tepat guna dapat dimanfaatkan bukan untuk satu jenis tanaman saja melainkan semua jenis bentuk tanaman pertanian.

3. Diharapkan kecamatan Batulicin dengan lokasi lahan yang luas mampu mengembangkan cara bertani dengan memanfaatkan teknologi mikrokontroler.

\section{Hasil dan Pembahasan}

Setelah pelaksanaan Pengabdian kepada Masyarakat selama 15 hari, maka PkM yang dilaksanakan ini berjalan dengan lancar, dari hasil kegiatan yang diperoleh adalah sebagai berikut:

1. Awalnya pertanian hidroponik yang digunakan dikecamatan Batulicin masih manual, setelah diperkenalkan hidroponik dengan metode mikrokontroler untuk tanaman selada sekarang pertanian hidroponik selada beberapa petani mulai menerapkannya.

2. Pada awalnya dikecamatan Batulicin, kurangnya pengetahuan tentang teknologi tepat guna, saat ini dengan memperkenalkan teknologi tepat guna berbasis mikrokontroler minat masyarakat lokal mulai meningkat.

3. Setelah diperkenalkan pengetahuan teknologi berbasis mikrokontroler ini beberapa masyarakat merasa terbantu dan mulai menerapkan untuk variasi tanaman yang berbeda.

4. Respon dari Kementrian Pendamping Desa khususnya kecamatan Batulicin, kabupaten Tanah Bumbu cenderung positif, sehingga memberikan masukan untuk 
menambahkan fitur baru pada rancangan alat yang penggunaan kedepan lebih user frendly dan mudah.

Berikut adalah dokumen foto tahap pembuatan dan tahap promosi rancangan alat
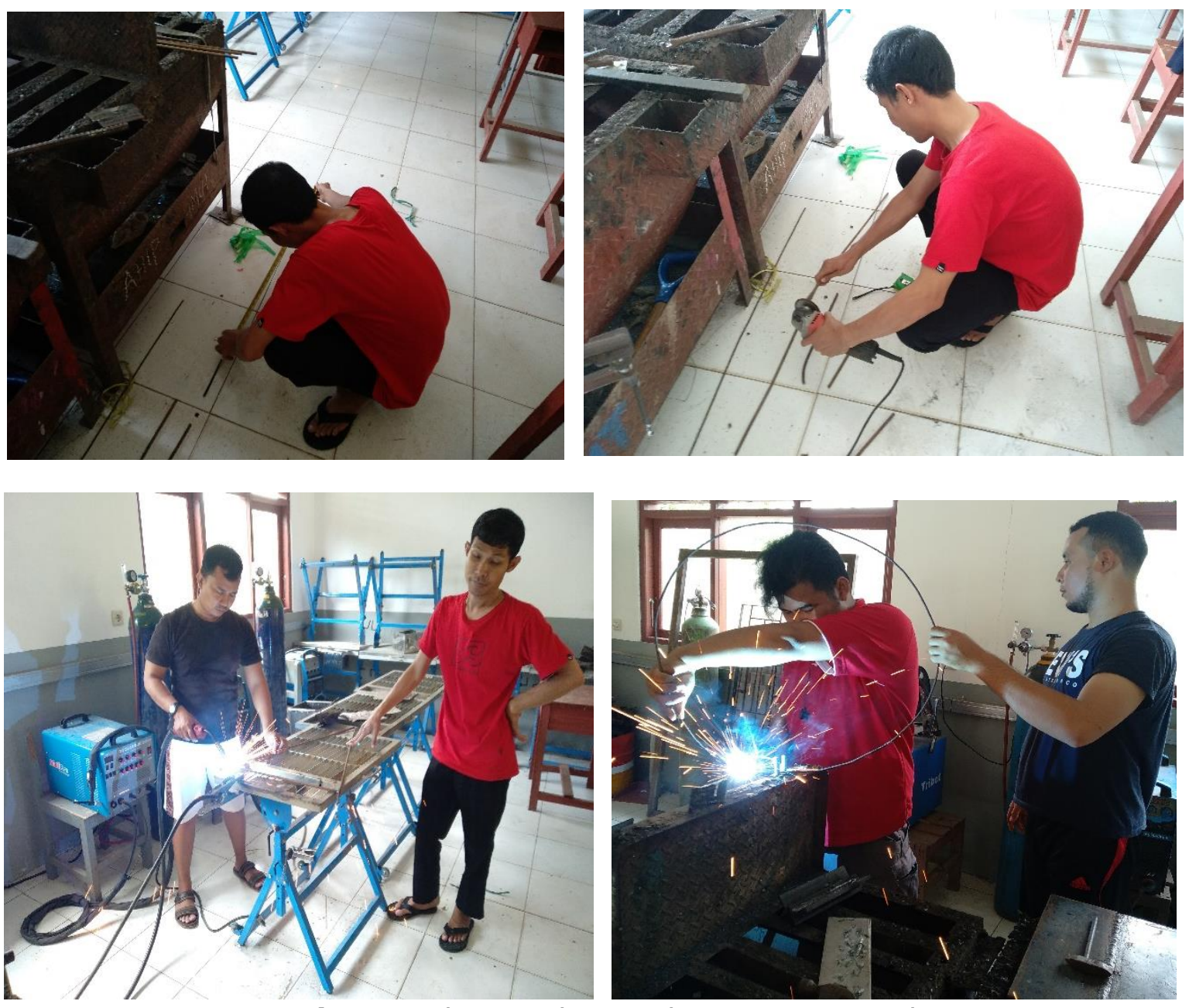

Gambar 1. Tahap pembuatan dan perancangan alat

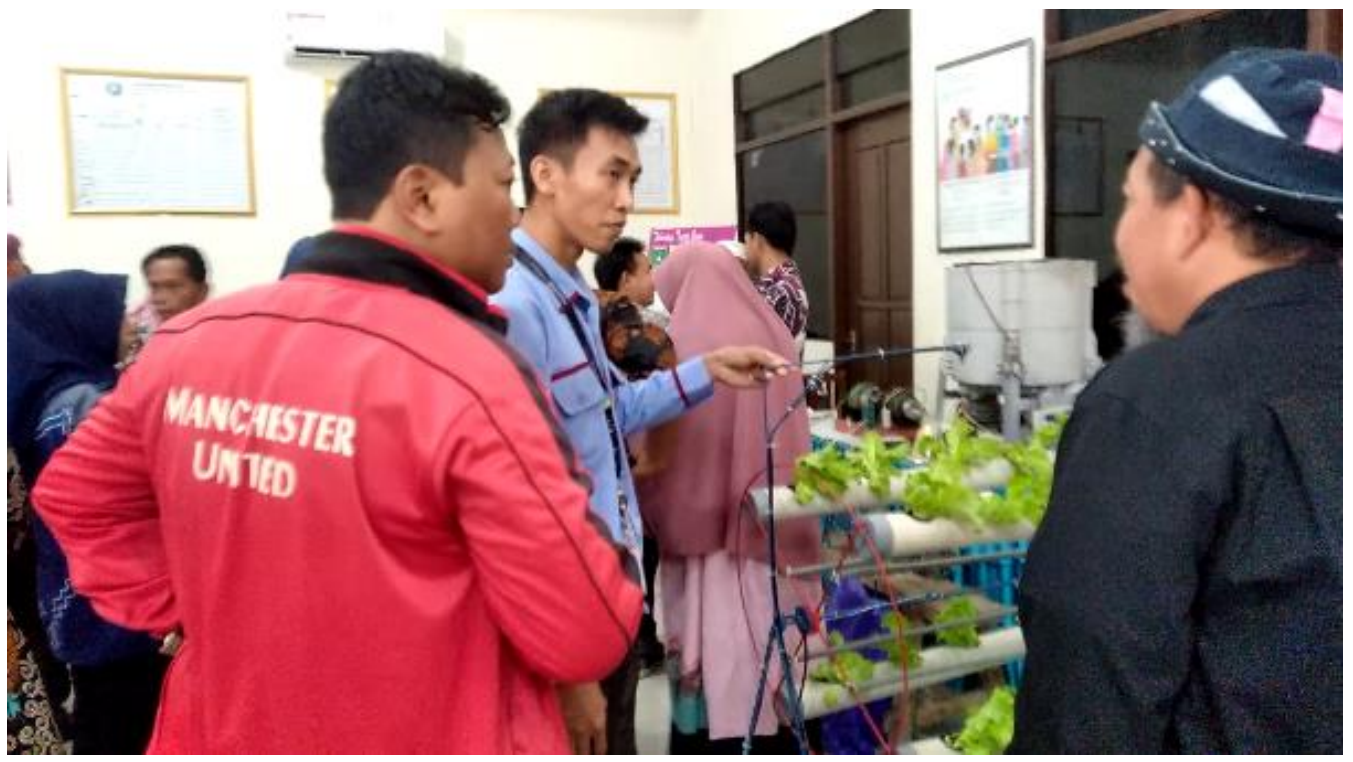

Gambar 2. Tahap promosi 


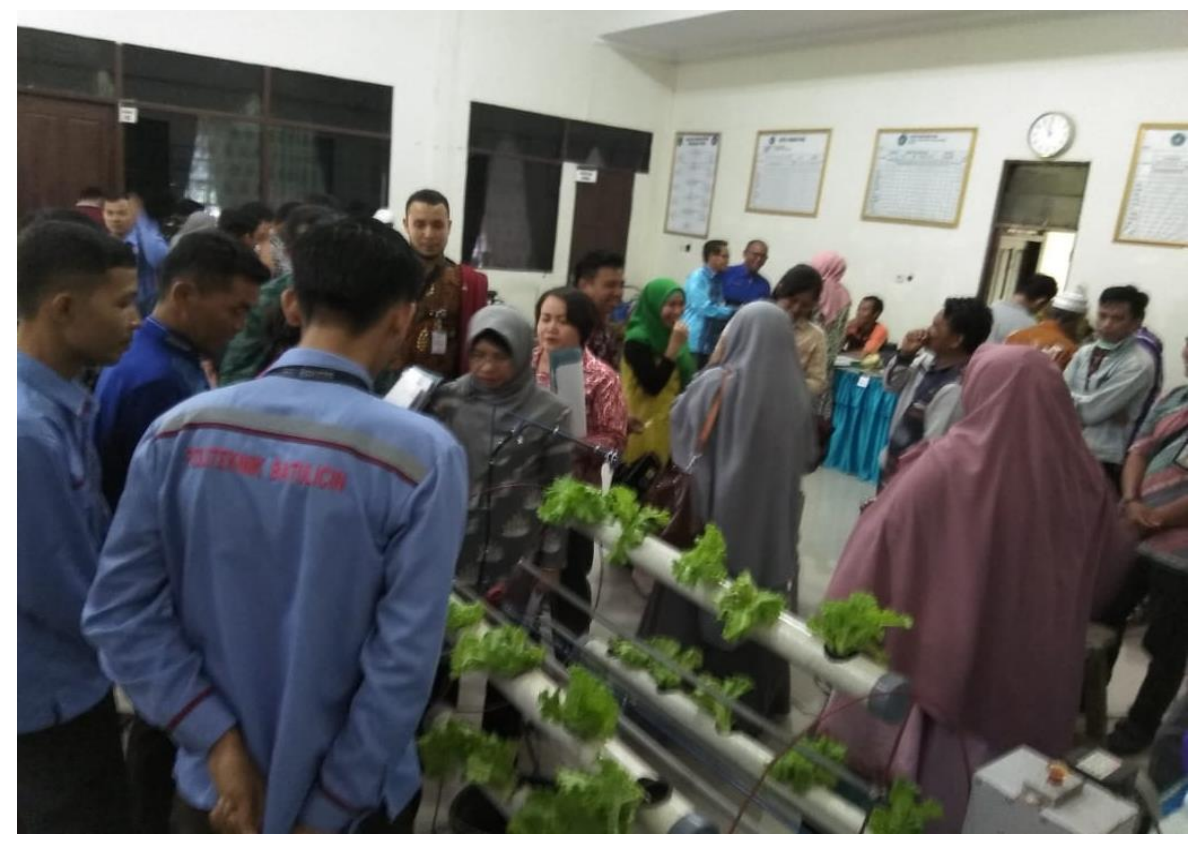

Gambar 3. Tahap pengenalan sistem kerja dari rancangan alat

\section{Kesimpulan}

Setelah dilaksanakannya kegiatan Pengabdian kepada Masyarakat (PkM) rancang bangun hidroponik berbasis mikrokontroler untuk tanaman selada di kecamatan Batulicin, kabupaten Tanah Bumbu, maka dapat ditarik kesimpulan sebagai berikut:

1. Pengabdian kepada Masyarakat ini memberikan solusi cerdas kepada masyrakat lokal tentang informasi dan teknologi yang berkembang seiring dengan waktu.

2. Memberikan pengetahuan kepada masyarakat lokal tentang teknologi berbasis mikrokontroler untuk hidroponik tanaman selada yang dapat mengefisienkan waktu dan membantu mempermudah dalam pengerjaan karena sistem kerjanya yang otomatis.

Pengabdian Kepada Masyarakat yang dilaksanakan di kecamatan Batulicin kami sebagai pelaksana mengevaluasi dan melakukan persiapan yang mendukung agar kegiatan berjalan dengan baik dan lancar tanpa kendala.

\section{Daftar Pustaka}

Sri Rohartati., Eri Subekti. (2020). Pelatihan Pembuatan Kripik Aneka Rasa Untuk Meningkatkan Umkm Di Desa Ciranjang Kecamatan Ciranjang Kabupaten Cianjur. BERNAS: Jurnal Pengabdian Kepada Masyarakat. Vol 1 No 3, 143-149, e-ISSN: 2721-9135, p-ISSN: 2716-442X.

Wikipedia.org. (2020). Batulicin Tanah Bumbu. (Online). Tersedia: https://id.wikipedia.org/wiki/Batulicin,_Tanah_Bumbu . Diakses Tanggal 25 Agustus 2020.

Tanahbumbukab.bps.go.id. (2020). Luas wilayah menurut kecamatan di kabupaten tanah bumbu.

(Online).

Tersedia: 
https://tanahbumbukab.bps.go.id/statictable/2017/04/24/839/luas-wilayahmenurut-kecamatan-di-kabupaten-tanah-bumbu-2015.html. Diakses Tanggal 28 Agustus 2020.

Pertanianku.com. (2020). Tumbuhan tanaman selada. (Online). Tersedia: https://www.pertanianku.com/syarat-tumbuh-tanaman-selada/. Diakses Tanggal 1 September 2020.

Obengplus.com. (2020). Kontrol suhu termometer otomatis digital. (Online). Tersedia: http://www.obengplus.com/artikel/articles/372/1/W1209-HW-557-kontrol-suhutermometer-otomatis-digital-mengatur-suhu-panas-dan-dingin-cara-setting.html. Diakses Tanggal 3 September 2020. 